\title{
Comparison of the Alzheimer's Disease Assessment Scale Cognitive Subscale and the Vascular Dementia Assessment Scale in Differentiating Elderly Individuals with Different Degrees of White Matter Changes
}

\author{
The LADIS Study
}

\begin{abstract}
Raija Ylikoski $^{\mathrm{a}}$ Hanna Jokinen $^{\mathrm{a}, \mathrm{b}}$ Pia Andersen ${ }^{\mathrm{a}}$ Oili Salonen $^{\mathrm{c}}$ Sofia Madureira $^{\mathrm{d}}$ Jose Ferro $^{\mathrm{d}}$ Frederik Barkhofe Wiesje van der Flier ${ }^{f}$ Reinhold Schmidt ${ }^{g}$ Franz Fazekas ${ }^{g}$ Philip Scheltens ${ }^{f}$ Gunhild Waldemar $^{\text {h }}$ Emilia Salvadori ${ }^{i}$ Leonardo Pantoni ${ }^{i}$ Domenico Inzitari ${ }^{i}$ Timo Erkinjuntti ${ }^{a}$ on behalf of the LADIS Study Group
\end{abstract}

\begin{abstract}
${ }^{a}$ Memory Research Unit, Department of Neurology, and ${ }^{b}$ Department of Psychology, University of Helsinki, and 'Helsinki Medical Imaging Center, Helsinki University Central Hospital, Helsinki, Finland; ${ }^{\mathrm{d}}$ Serviço de Neurologia,

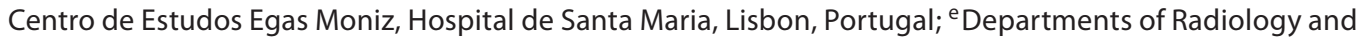
Image Analysis Centre, and f Department of Neurology and Alzheimer Centre, Vrije Universiteit Medical Centre, Amsterdam, The Netherlands; ${ }^{9}$ Department of Neurology and MRI Institute, Medical University, Graz, Austria; h Department of Neurology, Copenhagen University Hospital, Copenhagen, Denmark; 'Department of Neurological and Psychiatric Sciences, University of Florence, Florence, Italy
\end{abstract}

\section{Key Words}

Cognition • Neuropsychology • White matter changes •

Vascular Dementia Assessment Scale cognitive subscale

\begin{abstract}
Background/Aims: The Alzheimer's Disease Assessment Scale cognitive subscale (ADAS-cog) is a widely used rating instrument. The Vascular Dementia Assessment Scale cognitive subscale (VADAS-cog) includes additional tests reflecting mental speed and executive functions. The objective of this study was to compare the results of the two scales among subjects with various degrees of white matter hyperintensities (WMHs). Methods: In the multicentre, multinational Leukoaraiosis and Disability in the Elderly (LADIS) study, 616 non-disabled subjects between the ages of 65 and 84 were examined using MRI, the ADAS-cog and VADAScog. The WMH rating from the MRI divided the patients into groups of mild $(n=280)$, moderate $(n=187)$ and severe $(n=$
\end{abstract}

149) degrees of change. Results: Covariance analysis controlling for the effect of age and education revealed that the ADAS-cog differentiated only the mild and severe $\mathrm{WMH}$ groups, while the differences between all three groups were highly significant with the VADAS-cog. Conclusions: The VADAS-cog significantly differentiated between all the white matter groups. In comparison, the ADAS-cog differentiated only severe changes. Accordingly, the VADAS-cog may be a more sensitive endpoint in studies of patients with white matter load and vascular burden of the brain.

Copyright $\odot 2007$ S. Karger AG, Basel

\section{Introduction}

Progressive impairment of memory and other cognitive functions in age-related diseases has made it important to develop concise and easily applied global cognitive measurement tools. The Alzheimer's Disease Assessment

\section{KARGER}

Fax +41613061234 E-Mail karger@karger.ch www.karger.com

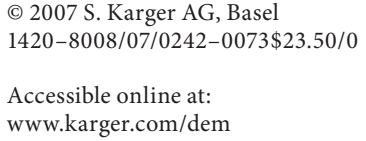

Ylikoski Raija

Department of Neurology, University of Helsinki

PO Box 340

FI-00029 HUS, Helsinki (Finland)

Tel. +35894717 2274, Fax +35894717 4009, E-Mail raija.ylikoski@hus.fi 
Scale (ADAS) was designed by Rosen et al. [1] in order to produce a rating instrument for detecting cognitive change in Alzheimer's disease (AD). The cognitive subtest (ADAS-cog) has proven to be sensitive to AD progression, especially at the moderate stage [1-4]. Based on the sensitivity, the ADAS-cog has been adopted for evaluation of treatment efficacy in randomised clinical trials (RCTs) and proven to be a significant outcome measure in trials with AD [5-7] as well as with Parkinson's disease [8]. A number of RCTs have shown favourable cognitive effects as measured with the ADAS-cog in vascular dementia (VAD) [9-12] and AD with cerebrovascular disease [13-16]. Widening the scope of research to mild AD and mild cognitive impairment (MCI), a need has arisen to develop additional tasks. Tasks such as delayed recall of a word list, maze and digit cancellation have been found to be impaired in mild AD [17], and the modified ADAS-cog has shown favourable treatment effects in MCI [18].

The ADAS-cog has marked advantages, based on its substantial data confirming reliability and validity and its use in measuring longitudinal change together with sensitivity to treatment effects. However, the data are mainly based on AD research. So far, little is known of its sensitivity in other conditions, like vascular cognitive impairment (VCI) [19], subcortical ischaemic vascular disease [20] or white matter hyperintensities (WMHs). In a series of patients with lacunar infarcts, white matter changes did not independently influence performance in the ADAS-cog [21]. However, in a larger series of subjects with WMHs, an association was found [22]. The ADAScog was developed to assess AD patients and may not sufficiently capture the specific cognitive deficits of other diseases. Both VCI and white matter changes have been specifically related to executive functions, attention and mental speed [23-26]. A revision of the ADAS-cog, called Vascular Dementia Assessment Scale cognitive subscale (VADAS-cog), has been proposed in order to provide a better measure in vascular conditions $[27,28]$. In addition to the original ADAS-cog developed by Rosen et al. [1], recommended additional tests include a delayed recall of a word list task, digit cancellation task, maze task, symbol digit test, digit span backward test and verbal fluency test (animal category) [28].

There is a growing need for more sensitive cognitive screening tools for elderly individuals in a variety of clinical entities. In addition, development of more sensitive outcome measures for clinical studies and RCTs is important. Studies of the sensitivity of the VADAS-cog are still few. The objective of the present study is to compare the results of the ADAS-cog and the VADAS-cog among subjects with various degrees of WMHs in the Leukoaraiosis and Disability in the Elderly (LADIS) study.

\section{Materials and Methods}

The LADIS study is a multicentre and multinational prospective follow-up study of initially non-disabled elderly patients with different degrees of age-related white matter changes (see detailed description in Pantoni et al. [29]). Baseline data were collected in 11 European centres. Subjects were entered into the study if neuroimaging revealed the presence of WMHs of any degree. Other inclusion criteria were an age of between 65 and 84; no or mild disability as assessed by the Instrumental Activities of Daily Living (IADL) scale [30] (none or only one domain affected); the presence of an informant, and agreement to sign an informed consent. Exclusion criteria were the presence of severe illness (e.g. cardiac disease, cancer, hepatic disease) or severe unrelated neurological diseases; leucoencephalopathies of non-vascular origin revealed by brain imaging; the presence of severe psychiatric disorders; the inability to give informed consent, or the inability or refusal to undergo cerebral MRI. The total number of subjects recruited was 639. Complete data from all needed tests were available for 616 subjects. Stratification of subjects was prespecified based on the degree of WMHs [29].

Clinical data were gathered using clinical and functional tests, including global functioning, motor, psychiatric, and activities of daily living measures. Background and clinical data in this study consisted of age, sex, education, history of stroke and major depression and activities of daily living measured by the IADL scale [30]. Cognitive assessment included global measures like Mini Mental State Examination (MMSE) [31], and ADAS$\operatorname{cog}$ [1] and VADAS-cog extensions [28] (see detailed description in Madureira et al. [32]). The ADAS-cog was designed according to Rosen et al. [1], except for the modification that the word lists were presented only once. The scoring system is the same as in the original version. The maximum score in 8 subtests is 5 , while the 2 word list tasks are scored according to words not recalled (maximum 10 and 12), and in orientation the maximum number of mistakes is 8 . The range of scores is from 0 to 70 , a higher score indicating lower performance. The VADAS-cog includes 6 additional subtests: the delayed recall of a word list task (10 words), the digit cancellation test (the number of correct digits cancelled in $45 \mathrm{~s}$ ), the maze task (the time to complete the task and the number of errors), the symbol digit test (the number of correct responses in $90 \mathrm{~s}$ ), the digit span backward test (the number of digits recalled backwards) and the verbal fluency test (animal category in $1 \mathrm{~min}$ ) [28]. The delayed recall of a word list is scored like other ADAS-cog items (number of words not recalled). In the 5 other additional tests, the range of raw scores is far too wide to be summarized for the total score, and these scores have to be transformed in order to be able to make a summary score for the VADAS-cog comparable to the ADAS-cog. Percentile scores can be applied and used in various settings [33], and are similar to the ADAS-cog subtest scores. The percentiles of raw scores for maze (time score) and digit span backward were analysed in 5 categories (every 20th percentile) and scored so that 1 represents 
the best performance and 5 the worst. The symbol digit test, the digit cancellation test and the verbal fluency test were similarly changed to percentiles, but in 10 categories (every 10th percentile) due to the large range of raw scores; 1 represents the best performance and 10 the worst (see Appendix 2 for the conversion). A subgroup of 195 subjects from the LADIS study group was used for transforming the VADAS-cog additional tests. The inclusion criteria for the standardization group were no global cognitive impairment (MMSE score = more than 26), independent in daily living (all IADL functions $=1$, i.e., no impairment) and no history of stroke or major depression. The mean age of this subgroup was 74 years $(\mathrm{SD}=5.3)$, the mean duration of education was 10.3 years $(\mathrm{SD}=3.4)$ and $143(73 \%)$ of the subjects were females.

MRI was studied according to the standard protocol. Scans were made on 0.5-tesla or 1.5-tesla scanners and the series included axial $\mathrm{T}_{2}$-weighted images [echo time (TE) 100-120 ms; repetition time (TR) 4,000-6,000 ms; voxel size $1 \times 1 \times 5-7.5$ $\mathrm{mm}^{3} ; 19-24$ slices]; axial fluid-attenuated inversion recovery images (TE 100-140 ms; TR 6,000-10,000 ms; inversion time 2,000$2,400 \mathrm{~ms}$; voxel size $1 \times 1 \times 5-7.5 \mathrm{~mm}^{3}$; $19-24$ slices), and a coronal or sagittal 3-dimensional $\mathrm{T}_{1}$ sequence (TE 4-7 ms; TR $10-25 \mathrm{~ms}$; flip angle $15-30^{\circ}$; voxel size $\left.1 \times 1 \times 1-1.5 \mathrm{~mm}^{3}\right)$. MRI data were collected centrally at the Image Analysis Centre of the Vrije Universiteit Medical Centre, Amsterdam, the Netherlands. All ratings were performed by an experienced rater (E.v.S.) blinded to the clinical data. The degree of WMH severity was rated on the fluid-attenuated inversion recovery images using the visual scale of Fazekas et al. [34]: mild $=1$ (punctuate), moderate $=2$ (early confluent), severe $=3$ (confluent). For a more detailed MRI protocol, see Pantoni et al. [29], van Straaten et al. [35], and van der Flier et al. [22].

The demographic characteristics and MMSE results of the three WMH groups were evaluated with analysis of variance and a $\chi^{2}$ test. The continuous items of the ADAS-cog were examined with analysis of variance, while the categorical items of the ADAScog were analysed by the $\chi^{2}$ test. The categorical variables were heavily weighted to a zero score, and a cut-off point of 2 was used for the categories 2-5. The additional tests included in the VADAScog were individually evaluated between the three WMH groups by univariate analysis of variance. The Pearson correlation was calculated between the possible confounding demographic factors and the ADAS-cog and the VADAS-cog tests. Furthermore, univariate analysis of covariance controlling for the effect of age and education was performed between the three WMH groups and the ADAS-cog and the VADAS-cog results. Finally, a stepwise discriminant analysis was performed for the additional VADAS-cog tests, in order to identify those subtests that contribute most to the differences between the WMH groups.

\section{Results}

The characteristics of the study sample in the three different white matter groups are presented in table 1. The white matter degree grew significantly with age, and there was also some variation with sex.

The ADAS-cog and the VADAS-cog and White Matter Lesions
The results for ADAS-cog items are presented in table 2 . Five out of 11 items showed significant results between the white matter groups. The categorical variables of construction, naming, apraxia, word finding and comprehension showed statistically significant differences between the three white matter groups.

Analysis of variance showed significant differences between the WMH groups in delayed recall, verbal fluency, symbol digit, digit cancellation and maze (table 3). We used the time score of the maze task, because the error score showed a floor effect [552 (90\%) of subjects with 0 ; 53 (8\%) with 1, and 11 (2\%) with 2 errors].

The association between the ADAS-cog and the VADAS-cog total scores and age and education was evaluated using Pearson correlation and between these tests and sex using analysis of variance (for a more detailed evaluation of background variables and cognitive tests, see Madureira et al. [32]). Age correlated significantly with the ADAS-cog $(r=0.16, \mathrm{p}<0.01)$ and the VADAS$\operatorname{cog}(\mathrm{r}=0.24, \mathrm{p}<0.01)$. Education correlated significantly with both the ADAS-cog $(r=-0.25, \mathrm{p}<0.01)$ and the VADAS- $\operatorname{cog}(\mathrm{r}=-0.42, \mathrm{p}<0.01)$. In a univariate analysis of variance, sex did not show a relationship with either cognitive scale (ADAS-cog: $\mathrm{F}=3.0, \mathrm{p}=0.08$; VADAS-cog: $\mathrm{F}=0.66, \mathrm{p}=0.41)$. With analysis of covariance, we evaluated the association between white matter changes and cognitive tests by controlling for the effects of age and education. The covariate-adjusted estimates of group means and pairwise comparisons are presented in figures 1 and 2. After controlling for age and education, the significance of the ADAS-cog diminished $(\mathrm{F}=3.9 ; \mathrm{p}=$ 0.02 ), and in pairwise analysis it was shown that only WMH group 1 and WMH group 3 significantly differed from each other. In the VADAS-cog, however, the differences remained highly significant even after controlling for age and education $(\mathrm{F}=16.2 ; \mathrm{p}=0.000)$, and statistical significance was revealed between all three degrees of WMHs (fig. 2). We repeated the analysis of covariance with the subgroup of subjects $(n=420$; WMH group 1 : $\mathrm{n}=163$, WMH group 2: $\mathrm{n}=132$, WMH group 3: $\mathrm{n}=125$ ) who were not enrolled in the test transformation group (Appendix 2). The ADAS-cog did not show a significant relationship with the white matter changes after controlling for the effects of age and education $(\mathrm{F}=0.96, \mathrm{p}=$ 0.38). The VADAS-cog test differed significantly between the WMH groups in the analysis of covariance $(\mathrm{F}=5.58$, $\mathrm{p}=0.004)$. A direct comparison of these tests would require a different setting and design. A rough estimate of how well these tests classify the subjects in the WMH groups was performed by discriminant function analysis. 
Table 1. Characteristics of the LADIS study group $(n=616)$ and differences among the three WMH groups (mild: WMH group 1; moderate: WMH group 2; severe: WMH group 3)

\begin{tabular}{|c|c|c|c|c|c|}
\hline & $\begin{array}{l}\text { Total } \\
(\mathrm{n}=616)\end{array}$ & $\begin{array}{l}\text { WMH group } 1 \\
(\mathrm{n}=280)\end{array}$ & $\begin{array}{l}\text { WMH group } 2 \\
(\mathrm{n}=187)\end{array}$ & $\begin{array}{l}\text { WMH group } 3 \\
(\mathrm{n}=149)\end{array}$ & $\mathrm{F}$ \\
\hline Age (mean $\pm S D)$, years & $73.9 \pm 5.1$ & $73.2 \pm 5.0$ & $74.3 \pm 5.2$ & $75.0 \pm 4.8$ & $6.5^{* *}$ \\
\hline Female & $340(55.2 \%)$ & $157(56.1 \%)$ & $113(60.4 \%)$ & $70(47 \%)$ & $6.2^{*}\left(\chi^{2}\right)$ \\
\hline Education (mean $\pm \mathrm{SD}$ ), years & $9.6 \pm 3.8$ & $9.8 \pm 3.7$ & $9.7 \pm 3.9$ & $9.3 \pm 3.9$ & 1.1 \\
\hline MMSE score (mean \pm SD) & $27.4 \pm 2.4$ & $27.7 \pm 2.0$ & $27.5 \pm 2.3$ & $26.7 \pm 2.9$ & $9.1^{* * *}$ \\
\hline
\end{tabular}

The ADAS-cog correctly classified $45.8 \%$ of subjects, while the VADAS-cog correctly classified $47.9 \%$ of subjects.

A stepwise discriminant analysis was performed to identify the combination of the VADAS-cog additional tests that best discriminate between the degrees of WMHs. The stepwise method selected digit cancellation ( $\mathrm{F}$ to enter $=26.9$; Wilks $\lambda=0.92$; exact $\mathrm{F}=26.9, \mathrm{p}=0.000$ ), followed by verbal fluency ( $\mathrm{F}$ to enter $=4.2$; Wilks $\lambda=0.91$; exact $F=15.3, p=0.000)$. No other variable entered in the analysis. The symbol digit test also had a high $\mathrm{F}$ to enter (22.6) at step 0, but as it highly correlated with the digit cancellation test $(r=0.75)$, it was not entered into the analysis.

\section{Discussion}

Examining the relationship between the ADAS-cog, the VADAS-cog and white matter changes in a large group of community-dwelling subjects with white matter changes, we found that 5 out of 11 tasks of the ADAS-cog showed an association with the degree of WMHs. The summary score of the ADAS-cog was different in the mild versus severe $\mathrm{WMH}$ groups after controlling for the effects of age and education, but not in the mild versus moderate or moderate versus severe $\mathrm{WMH}$ groups. In contrast, in the VADAS-cog, 5 out of 6 additional tests showed a significant relationship with WMH severity. The total score of the VADAS-cog differed highly significantly in all three white matter groups, even after controlling for age and education. The VADAS-cog proved to be a more sensitive measure to reflect the white matter load than the ADAS-cog. Discriminant analysis showed that the digit cancellation and verbal fluency tests were the most useful additional subtests in the VADAS-cog in showing differences between the WMH groups. Tests that measure processing speed and executive functions showed relative importance in association with white matter changes in this study group.

This is the first study applying the modification of the ADAS-cog proposed by Ferris [27, 28], and no standardised summary score system has been developed. The delayed recall of a word list is scored like other ADAS-cog items (number of words not recalled). The 5 other additional tests differ in the scoring system, and the raw scores cannot be summarised for the total score. The range of the additional test scores is wider and more variable compared to the other ADAS-cog items and the frequency distribution corresponds to a normal curve. We did not want to use any arbitrary cut-off points; instead we used the percentile scores when transforming the raw scores [33]. In this way, the individual tests could be summarised similarly to the ADAS-cog system.

In a few previous studies, the additional tasks of the ADAS-cog have been analysed separately $[17,36]$. In some, the additional task of delayed recall of a word list has been added to the ADAS-cog score [18]. The digit cancellation test proved to be a useful additional task in measuring mild Alzheimer patients [17], while in a series of MCI subjects the additional tests of symbol digit, digit cancellation and verbal fluency did not show significant results [36]. Various studies have proven that the relationship between white matter changes and cognition is specific, concentrating on executive functions, attention and mental speed $[22,25]$. Executive deficits have also been found to be one of the most prominent features in subcortical ischaemic vascular disease [20,24]. VCI has been related to deficits in attention, executive functions, and slowing of performance [19]. Executive and psychomotor 
Table 2. Results of the LADIS study group $(n=616)$ in the ADAS-cog test and subtests and the differences among the three WMH groups (mild: WMH group 1; moderate: WMH group 2; severe: WMH group 3)

\begin{tabular}{|c|c|c|c|c|c|}
\hline & $\begin{array}{l}\text { Total } \\
(\mathrm{n}=616)\end{array}$ & $\begin{array}{l}\text { WMH } \\
\text { group } 1 \\
(n=280)\end{array}$ & $\begin{array}{l}\text { WMH } \\
\text { group } 2 \\
(n=287)\end{array}$ & $\begin{array}{l}\text { WMH } \\
\text { group } 3 \\
(n=149)\end{array}$ & \\
\hline \multicolumn{6}{|l|}{ ADAS-cog } \\
\hline Word recall & $5.1 \pm 1.6$ & $5.0 \pm 1.7$ & $4.9 \pm 1.5$ & $5.3 \pm 1.7$ & 1.9 \\
\hline Word recognition & $2.8 \pm 2.4$ & $2.7 \pm 2.2$ & $2.9 \pm 2.5$ & $2.9 \pm 2.5$ & 0.8 \\
\hline Orientation & $0.3 \pm 1.0$ & $0.2 \pm 0.8$ & $0.4 \pm 1.3$ & $0.4 \pm 0.9$ & 1.7 \\
\hline \multicolumn{6}{|l|}{ Subtests } \\
\hline \multicolumn{6}{|l|}{ Following command } \\
\hline 0 & $437(71)$ & $196(70)$ & $139(74)$ & $102(68)$ & \\
\hline 1 & $153(25)$ & $77(27)$ & $40(21)$ & $36(24)$ & \\
\hline $2-5$ & $26(4.2)$ & $7(2.5)$ & $8(4.3)$ & $11(7.4)$ & 7.6 \\
\hline \multicolumn{6}{|l|}{ Construction } \\
\hline 0 & $319(52)$ & $165(59)$ & $86(46)$ & $68(45)$ & \\
\hline 1 & $264(43)$ & $107(38)$ & $82(44)$ & $75(50)$ & \\
\hline $2-5$ & $23(5)$ & $8(3)$ & $19(10)$ & $6(4)$ & $20.3^{* *}$ \\
\hline \multicolumn{6}{|l|}{ Naming } \\
\hline 0 & $517(84)$ & $245(87)$ & $156(83)$ & $116(78)$ & \\
\hline 1 & $90(15)$ & $33(12)$ & $30(16)$ & $27(18)$ & \\
\hline $2-5$ & $9(1.5)$ & $2(1)$ & $1(0.5)$ & $6(4)$ & $13.0^{*}$ \\
\hline \multicolumn{6}{|l|}{ Ideational apraxia } \\
\hline 0 & $532(86)$ & $255(91)$ & $154(82)$ & $123(83)$ & \\
\hline 1 & $62(10)$ & $19(7)$ & $23(12)$ & $20(13)$ & \\
\hline $2-5$ & $22(3.6)$ & $6(2.2)$ & $10(5.4)$ & $6(4)$ & $10.2^{*}$ \\
\hline \multicolumn{6}{|c|}{ Remembering instructions } \\
\hline 0 & $532(86)$ & $246(88)$ & $164(88)$ & $122(82)$ & \\
\hline 1 & $54(9)$ & $25(9)$ & $14(7.5)$ & $15(10)$ & \\
\hline $2-5$ & $30(5)$ & $9(3.3)$ & $9(5)$ & $12(8)$ & 5.8 \\
\hline \multicolumn{6}{|l|}{ Spoken language } \\
\hline 0 & $563(91)$ & $262(94)$ & $173(92)$ & $128(86)$ & \\
\hline 1 & $41(7)$ & $13(5)$ & $11(6)$ & $17(11)$ & \\
\hline $2-5$ & $12(2)$ & $5(2)$ & $3(1.6)$ & $4(2.7)$ & 8.1 \\
\hline \multicolumn{6}{|l|}{ Word finding } \\
\hline 0 & $509(83)$ & $242(86)$ & $159(85)$ & $108(72)$ & \\
\hline 1 & $86(14)$ & $32(11)$ & $24(13)$ & $30(20)$ & \\
\hline $2-5$ & $21(3.4)$ & $6(2)$ & $4(2)$ & $11(7.3)$ & $17.1^{* *}$ \\
\hline \multicolumn{6}{|l|}{ Comprehension } \\
\hline 0 & $489(79)$ & $239(85)$ & $145(77)$ & $105(70)$ & \\
\hline 1 & $80(13)$ & $28(10)$ & $22(12)$ & $30(20)$ & \\
\hline $2-5$ & $47(7.6)$ & $12(4.6)$ & $20(11)$ & $14(9.4)$ & $17.0^{* *}$ \\
\hline ADAS-cog total & $10.4 \pm 5.2$ & $9.6 \pm 4.3$ & $10.6 \pm 5.7$ & $11.5 \pm 5.9$ & $6.3^{* *}$ \\
\hline
\end{tabular}

Statistical analysis between the three WMH groups: F values (univariate analysis of variance) for ADAS-cog and ADAS-cog total and $\chi^{2}$ for the subtests. ${ }^{*} \mathrm{p}<0.05$; ${ }^{* *} \mathrm{p}<$ 0.01 . Figures in parentheses are percentages. difficulties have been found to be similar in VCI and VAD, only differing in the degree of severity [37]. The ADAS-cog has shown to be a significant cognitive outcome measure in previous RCTs on VAD [9-12] and AD with cerebrovascular disease [13-16]. However, more sensitive cognitive screening tools and more sensitive outcome measures are needed in order to detect even mild or specific cognitive changes and beneficial treatment effects. The VADAS-cog aims to measure cognitive domains affected in vascular conditions. We found that the VADAS-cog had a highly significant association with the three degrees of WMHs, while the ADAS-cog showed 


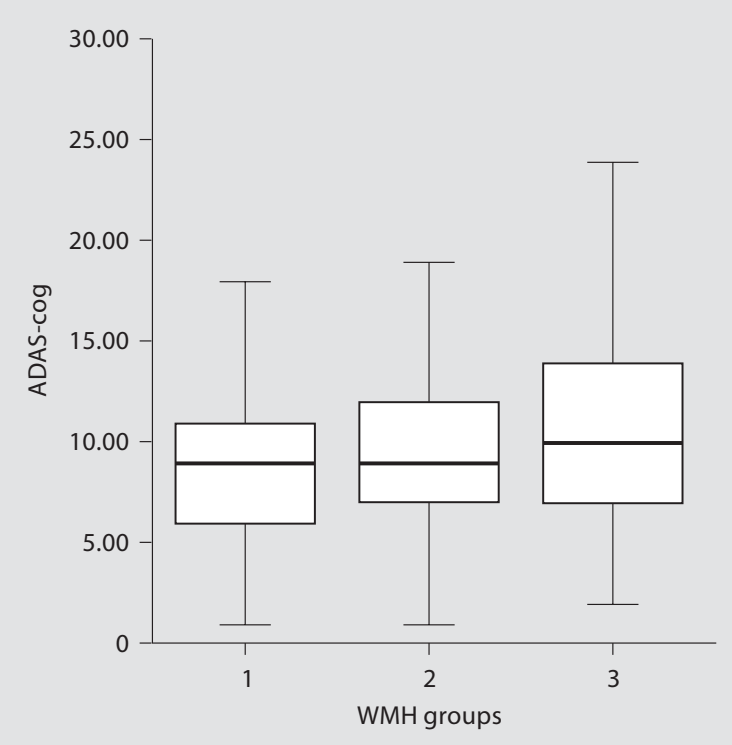

Fig. 1. Analysis of covariance between white matter changes mild WMHs (group 1), moderate WMHs (group 2), severe WMHs (group 3) - and the ADAS-cog summary score. Covariates are age and education. The corrected means (standard errors) are: WMH group $1=9.8(0.3)$; WMH group $2=10.5(0.4)$; WMH group $3=$ $11.2(0.4) ; \mathrm{F}=3.9, \mathrm{p}=0.02$. The mean difference between $\mathrm{WMH}$ group 1 and $\mathrm{WMH}$ group 2 is $-0.7(\mathrm{p}=0.12)$, between $\mathrm{WMH}$ group 2 and $\mathrm{WMH}$ group $3-0.68(\mathrm{p}=0.22)$ and between $\mathrm{WMH}$ group 1 and WMH group $3-1.4(\mathrm{p}=0.01)$.

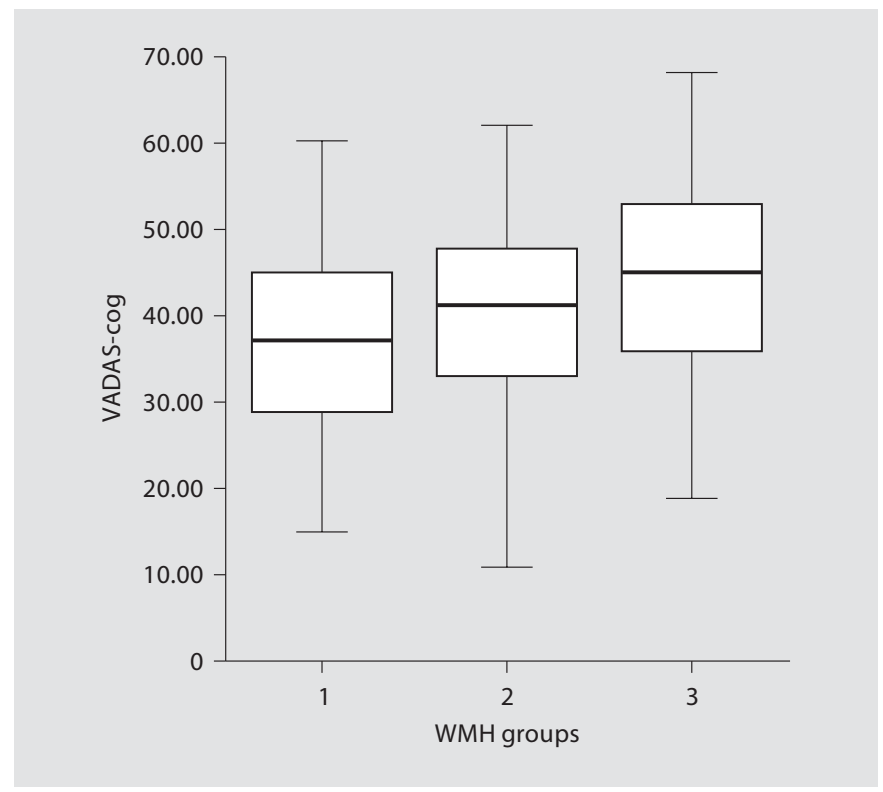

Fig. 2. Analysis of covariance between white matter changes mild WMHs (group 1), moderate WMHs (group 2), severe WMHs (group 3) - and the VADAS-cog summary score. Covariates are age and education. The corrected means (standard errors) are: WMH group $1=38.7$ (0.6); WMH group $2=41.9(0.8)$; WMH group $3=44.9(0.9) ; \mathrm{F}=16.2, \mathrm{p}=0.000$. The mean difference between WMH group 1 and WMH group 2 is $-3.1(\mathrm{p}=0.002)$, between WMH group 2 and WMH group $3-3.1(\mathrm{p}=0.01)$ and between WMH group 1 and WMH group $3-6.2(\mathrm{p}=0.000)$.
Table 3. Results of the LADIS study group $(n=616)$ in the VADAS-cog test and subtests and the differences among the three WMH groups (mild: WMH group 1; moderate: WMH group 2; severe: WMH group 3)

\begin{tabular}{lccccc}
\hline & Total & $\begin{array}{l}\text { WMH } \\
\text { group 1 } \\
(\mathrm{n}=616)\end{array}$ & $\begin{array}{l}\text { WMH } \\
\text { group 2 } \\
(\mathrm{n}=187)\end{array}$ & $\begin{array}{l}\text { WMH } \\
\text { group 3 } \\
(\mathrm{n}=149)\end{array}$ & F \\
\hline Delayed recall & $5.8 \pm 2.4$ & $5.5 \pm 2.4$ & $6.1 \pm 2.3$ & $6.1 \pm 2.4$ & $5.5^{*}$ \\
Digit span & $5.46 \pm 1.7$ & $5.5 \pm 1.7$ & $5.6 \pm 1.7$ & $5.1 \pm 1.7$ & 4.0 \\
Verbal fluency & $19.1 \pm 6.2$ & $20.1 \pm 6.0$ & $19.4 \pm 6.0$ & $16.9 \pm 6.2$ & $13.7^{* *}$ \\
Symbol digit & $26.9 \pm 10.9$ & $29.7 \pm 10.7$ & $26.1 \pm 10.4$ & $22.6 \pm 0.7$ & $22.6^{* *}$ \\
Digit cancellation & $19.6 \pm 6.7$ & $21.5 \pm 7.0$ & $19.0 \pm 6.2$ & $16.9 \pm 5.7$ & $26.9^{* *}$ \\
Maze & $7.3 \pm 5.9$ & $6.7 \pm 4.6$ & $7.1 \pm 5.6$ & $8.6 \pm 8.0$ & $4.9^{*}$ \\
VADAS-cog & $41.2 \pm 12.6$ & $38.1 \pm 11.8$ & $42.0 \pm 12.5$ & $45.9 \pm 12.4$ & $20.7^{* *}$ \\
\hline
\end{tabular}

$\mathrm{F}=$ Univariate analysis of variance between the three WMH groups.

${ }^{*} \mathrm{p}<0.05 ;{ }^{* *} \mathrm{p}<0.001$. significant results only between the mild versus severe WMHs. The additional tasks measure executive functions, flexibility, attention and psychomotor speed, and these tests significantly improved the sensitivity of the ADAS-cog in measuring the subjects' white matter changes. The term 'executive functions' has been applied to a set of higher-order cognitive processes that control, integrate, organize and maintain cognitive abilities. Various methods have been used in assessing different aspects of executive functions. Verbal fluency reflects 
memory retrieval strategies and mental flexibility [38, 39]. The digit span backward test has been used as a measure of working memory [40]. The maze test, which usually includes various increasingly complex tasks, is affected among other things by planning abilities [40]. The digit cancellation and the symbol digit tests are thought to reflect attention and speed of performance as well as flexibility [41]. Further development of the VADAS-cog might be indicated according to our results. The digit span backward test did not differ between the three study groups. The maze task was problematic, because the error score showed heavy floor effects (most subjects with no errors). The time score was not very sensitive in this study sample. Our results revealed that the best discrimination could be achieved by the digit cancellation and verbal fluency tests. This is a preliminary study presenting results of the VADAS-cog test. More research is needed with different diagnostic groups and sensitivity/specificity estimations in order to find the best combination. Our results indicate that both attention/speed, measured by digit cancellation, and executive functions/flexibility, measured by verbal fluency, are important domains when studying white matter changes, while the digit span backward test and the maze task were not so useful in this study design.

Our results are limited to independent, community-living subjects with white matter diseases. More research with subcortical ischaemic vascular disease, VCI and VAD subjects is required to verify the usefulness of the VADAScog, and if needed to modify the test composition. Although the additional tests of the VADAS-cog have not been related to MCI [36], their usefulness in detecting cognitive changes and treatment effects in mild AD [17] could be important. The VADAS-cog is based on the ADAS-cog, building upon the substantial data confirming its validity and longitudinal sensitivity. A limitation of our study design was that it included only one learning trial of the word list task in ADAS-cog. This may affect the scores in this item and should be taken into account when evaluating the results. The additional tests in the VADAS-cog are also widely used and known neuropsychological tests. Extensive research work exists of the ADAS-cog and of the individual additional tests in the VADAS-cog. So far, little research has been done of the total score of the VADAS-cog. Our results need to be validated in future studies, and knowledge of its sensitivity to change in longitudinal studies is also needed. The strengths of this study include a well-characterised population, a large sample size and MRI ratings performed by a single centre.

The ADAS-cog and the VADAS-cog and White Matter Lesions
Most clinical trials have adopted cognitive screening assessments that were originally developed to assess treatment effects in AD. Executive dysfunction, slowing of performance or attention have a minimal impact on these scales. Detecting cognitive changes and treatment effects, even if they are limited to certain cognitive domains, would increase the sensitivity of the cognitive screening tests both in clinical settings and RCTs. Our results showed that the VADAS-cog, and especially the additional tests measuring processing speed and executive functions, had a highly significant relationship with white matter load.

\section{Acknowledgment}

The authors would like to acknowledge the commitment and useful advice of Prof. David J. Libon (New Jersey Institute for Successful Aging, University of Medicine and Dentistry of New Jersey, USA) during the preparation of the manuscript.

\section{Appendix 1: List of Participants in the LADIS Study}

Helsinki, Finland (Memory Research Unit, Department of Neurology, Helsinki University): Timo Erkinjuntti, MD, PhD; Tarja Pohjasvaara, MD, PhD; Pia Pihanen, MD; Raija Ylikoski, PhD; Hanna Jokinen, Lic. Psych.; Meija-Marjut Somerkoski, M. Psych.; Riitta Mäntylä, MD, PhD; Oili Salonen, MD, PhD. Graz, Austria (Department of Neurology and MRI Institute, Medical University): Franz Fazekas, MD; Reinhold Schmidt, MD; Stefan Ropele, PhD; Alexandra Seewann, MD; Katja Petrovic, MagPsychol; Ulrike Garmehi. Lisbon, Portugal (Serviço de Neurologia, Centro de Estudos Egas Moniz, Hospital de Santa Maria): José M. Ferro, MD, PhD; Ana Verdelho, MD; Sofia Madureira, PsyD. Amsterdam, The Netherlands (Department of Neurology, VU Medical Centre): Philip Scheltens, MD, PhD; Ilse van Straaten, MD; Alida Gouw, MD; Wiesje van der Flier, PhD; Frederik Barkhof, MD, PhD. Gothenburg, Sweden (Institute of Clinical Neuroscience, Goteborg University): Anders Wallin, MD, PhD; Michael Jonsson, MD; Karin Lind, MD; Arto Nordlund, PsyD; Sindre Rolstad, PsyD; Kerstin Gustavsson, RN. Huddinge, Sweden (Neurotec Department, Section of Clinical Geriatrics, Karolinska Universitetssjukhuset): Lars-Olof Wahlund, MD, PhD; Militta Crisby, MD, PhD; Anna Pettersson, physiotherapist; Kaarina Amberla, PsyD. Paris, France (Department of Neurology, Hôpital Lariboisière): Hugues Chabriat, MD, PhD; Ludovic Benoit, MD; Karen Hernandez, Solene Pointeau, Annie Kurtz, Daniel Reizine, MD. Mannheim, Germany (Department of Neurology, University of Heidelberg, Klinikum Mannheim): Michael Hennerici, MD; Christian Blahak, MD; Hansjorg Baezner, MD; Martin Wiarda, PsyD; Susanne Seip, RN. Copenhagen, Denmark (Copenhagen University Hospital, Memory Disorders Research Unit, Department of Neurology, Rigshospitalet, and the Danish Magnetic Resonance Research Centre, Hvidovre Hospital): Gunhild Waldemar, MD, DMSc; Egill Rostrup, MD, 
MSc; Charlotte Ryberg, MSc; Tim Dyrby, MSc; Olaf B. Paulson, MD, DMSc. Newcastle-upon-Tyne, UK (Institute for Ageing and Health, University of Newcastle): John O'Brien, DM; Sanjeet Pakrasi, MRCPsych; Thais Minnet, PhD; Michael Firbank, PhD; Jenny Dean, PhD; Pascale Harrison, BSc; Philip English, DCR. The coordinating centre is in Florence, Italy (Department of Neurological and Psychiatric Sciences, University of Florence): Domenico Inzitari, MD (Study Coordinator); Leonardo Panto- ni, MD, PhD; Anna Maria Basile, MD; Giovanna Carlucci, MD, PhD; Michela Simoni, MD; Giovanni Pracucci, MD; Monica Martini, MD; Eliana Magnani, MD; Anna Poggesi, MD; Luciano Bartolini, PhD; Emilia Salvadori, PhD; Marco Moretti, MD; Mario Mascalchi, MD, PhD. The LADIS Steering Committee is formed by Domenico Inzitari, MD, Timo Erkinjuntti, MD, $\mathrm{PhD}$, Philip Scheltens, MD, PhD, Marieke Visser, MD, PhD, and Peter Langhorne, $\mathrm{PhD}$.

Appendix 2. Scaled scores, based on the percentile scores for the 5 additional VADAS-cog tests

\begin{tabular}{|c|c|c|c|c|c|c|c|c|c|}
\hline \multicolumn{2}{|c|}{ Symbol digit } & \multicolumn{2}{|c|}{ Digit cancellation } & \multicolumn{2}{|c|}{ Verbal fluency } & \multicolumn{2}{|c|}{ Digit span } & \multicolumn{2}{|c|}{ Maze } \\
\hline $\begin{array}{l}\text { raw } \\
\text { score }\end{array}$ & $\begin{array}{l}\text { scaled } \\
\text { score }\end{array}$ & $\begin{array}{l}\text { raw } \\
\text { score }\end{array}$ & $\begin{array}{l}\text { scaled } \\
\text { score }\end{array}$ & $\begin{array}{l}\text { raw } \\
\text { score }\end{array}$ & $\begin{array}{l}\text { scaled } \\
\text { score }\end{array}$ & $\begin{array}{l}\text { raw } \\
\text { score }\end{array}$ & $\begin{array}{l}\text { scaled } \\
\text { score }\end{array}$ & $\begin{array}{l}\text { raw } \\
\text { score }\end{array}$ & $\begin{array}{l}\text { scaled } \\
\text { score }\end{array}$ \\
\hline $0-19$ & 10 & $0-14$ & 10 & $0-15$ & 10 & $0-4$ & 5 & $1-3$ & 1 \\
\hline $20-25$ & 9 & $15-17$ & 9 & $16-17$ & 9 & 5 & 4 & 4 & 2 \\
\hline $26-28$ & 8 & $18-19$ & 8 & 18 & 8 & 6 & 3 & 5 & 3 \\
\hline $29-30$ & 7 & 20 & 7 & $19-20$ & 7 & $7-8$ & 2 & $6-7$ & 4 \\
\hline $31-32$ & 6 & $21-22$ & 6 & 21 & 6 & $9-$ & 1 & $8-$ & 5 \\
\hline $33-35$ & 5 & 23 & 5 & $22-23$ & 5 & & & & \\
\hline $36-37$ & 4 & $24-25$ & 4 & $24-25$ & 4 & & & & \\
\hline $38-39$ & 3 & $26-27$ & 3 & 26 & 3 & & & & \\
\hline $40-44$ & 2 & $28-30$ & 2 & $27-29$ & 2 & & & & \\
\hline $45-$ & 1 & $31-$ & 1 & $30-$ & 1 & & & & \\
\hline
\end{tabular}

Subjects, $\mathrm{n}=195$ : MMSE score = more than 26, all IADL functions = 1, no stroke, no major depression.

\section{References}

1 Rosen WG, Mohs RC, Davis KL: A new rating scale for Alzheimer's disease. Am J Psychiatry 1984;141:1356-1364.

-2 Doraiswamy PM, Kaiser L, Bieber F, Garman RL: The Alzheimer's Disease Assessment Scale: evaluation of psychometric properties and patterns of cognitive decline in multicenter clinical trials of mild to moderate Alzheimer's disease. Alzheimer Dis Assoc Disord 2001;15:174-183.

-3 Stern RG, Mohs RC, Davidson M, Schmeidler J, Silverman J, Kramer-Ginsberg E, et al: A longitudinal study of Alzheimer's disease: measurement, rate and predictors of cognitive deterioration. Am J Psychiatry 1994;151: 390-396.

$\checkmark 4$ Youn JC, Lee DY, Kim KW, Lee JH, Jhoo JH, Lee KU, Ha J, Woo JI: Development of the Korean version of Alzheimer's Disease Assessment Scale (ADAS-K). Int J Geriatr Psychiatry 2002; 17:797-803.

5 Farlow MR, Lane R, Kudaravalli S, He Y: Differential qualitative responses to rivastigmine in APOE E4 carriers and noncarriers. Pharmacogenomics J 2004;4:332-335.
6 Kemp PM, Holmes C, Hoffman S, Wilkinson S, Zivanovic M, Thom J, Bolt L, Fleming J, Wilkinson DG: A randomised placebo controlled study to assess the effects of cholinergic treatment on muscarinic receptors in Alzheimer's disease. J Neurol Neurosurg Psychiatry 2003;74:1567-1570.

7 Lyketsos CG, Reichman WE, Kershaw P, Zhu Y: Long-term outcomes of galantamine treatment in patients with Alzheimer's disease. Am J Geriatr Psychiatry 2004;12:473482.

$\checkmark 8$ Emre M, Aarsland D, Albanese A, Byrne EJ, Deuschl G, De deyn PP, Durif F, Kulisevsky J, van Laar T, Lees A, Poewe W, Robillard A, Rosa MM, Wolters E, Quarg P, Tekin S, Lane $\mathrm{R}$ : Rivastigmine for dementia associated with Parkinson's disease. N Engl J Med 2004; 351:2509-2518.

-9 Orgogozo J-M, Rigaud A-S, Stöffler A, Möbius H-J, Forette F: Efficacy and safety of memantine in patients with mild to moderate vascular dementia. A randomized, placebocontrolled trial (MMM300). Stroke 2002;33. 1834-1839.
10 Pratt RD, Perdomo CA; the Donepezil VaD 307 and 308 Study Groups: Donepezil-treated patients with probable vascular dementia demonstrate cognitive benefits. Ann NY Acad Sci 2002;977:513-522.

-11 Wilcock G, Möbius HJ, Stöffler A; on behalf of the MMM 500 Group: A double-blind, placebo-controlled multicentre study of memantine in mild to moderate vascular dementia (MMM 500). Int Clin Psychopharmacol 2002;17:297-305.

12 Wilkinson D, Doody R, Helme R, Taubman K, Mintzer J, Kertesz A, Pratt RD; the Donepezil 308 Study Group: Donpezil in vascular dementia. A randomized, placebo-controlled study. Neurology 2003;61:479-486.

13 Erkinjuntti T, Kurz A, Small GW, Gauthier S, Bullock R, Lilienfeld S, Damaraju CV: Efficacy of galantamine in probable vascular dementia and Alzheimer's disease combined with cerebrovascular disease: a randomised trial. Lancet 2002;359:1283-1290.

14 Erkinjuntti T, Kurz A, Small GW, Bullock R, Lilienfeld S, Damaraju CV: An open-label extension trial of galantamine in patients with probable vascular dementia and mixed dementia. Clin Ther 2003;25:1765-1782. 
15 Lilienfeld S, Kurz A: Broad therapeutic benefits in patients with probable vascular dementia or Alzheimer's disease with cerebrovascular disease treated with galantamine. Ann NY Acad Sci 2002;977:487-492.

-16 Small G, Erkinjuntti T, Kurz A, Lilienfeld S: Galantamine in the treatment of cognitive decline in patients with vascular dementia or Alzheimer's disease with cerebrovascluar disease. CNS Drugs 2003;17:905-914.

$\checkmark 17$ Mohs RC, Knopman D, Petersen RC, Ferris $\mathrm{SH}$, Ernesto C, Grundman M, Sano M, Bieliauskas L, Geldmacher D, Clark C, Thal L: Development of cognitive instruments for use in clinical trials of antidementia drugs: additions to the Alzheimer's Disease Assessment Scale that broaden its scope. Alzheimer Dis Assoc Disord 1997;11:S13-S21.

18 Salloway S, Ferris S, Kluger A, Goldma R, Grising T, Kumar D, Richardson S: Efficacy of donepezil in mild cognitive impairment. A randomized placebo-controlled tiral. Neurology 2004;63:651-657.

-19 O’Brien JT, Erkinjuntti T, Reisberg B, Roman G, Sawada T, Pantoni L, Bowier JV, Ballard C, DeCarli C, Gorelick PB, Rockwood K, Burns A, Gauthier S, DeKosky S: Vascular cognitive impairment. Lancet Neurol 2003; 2:89-98.

-20 Roman GC, Erkinjuntti T, Wallin A, Pantoni L, Chui HC: Subcortical ischaemic vascular dementia. Lancet Neurol 2002;1:426-436.

-21 Wen HM, Mok VCT, Fan YH, Lam WWM, Tang W, Wong A, Huang RX, Wong KS: Effect of white matter changes on cognitive impairment in patients with lacunar infarcts. Stroke 2004;3:1826-1830.

22 Van der Flier WM, van Straaten ECW, Barkhof F, Verdelho A, Madureira S, Pantoni L, Inzitari D, Erkinjuntti T, Crisby M, Waldemar G, Schmidt R, Fazekas F, Scheltens P: Small vessel disease and general cognitive function in nondisabled elderly: the LADIS Study. Stroke 2005;36:2116-2120.

-23 DeCarli C, Murphy DG, Tranh M, Grady CL, Haxby JV, Gillette JA, Salerno JA, GonzalesAviles A, Horwitz B, Rapoport SI, et al: The effect of white matter hyperintensity volume on brain structure, cognitive performance, and cerebral metabolism of glucose in 51 healthy adults. Neurology 1995;45:20772084.
24 Jokinen H, Kalska H, Mäntylä R, Pohjasvaara T, Ylikoski R, Hietanen M, Salonen O, Kaste M, Erkinjuntti T: Cognitive profile of subcortical ischaemic vascular disease. J Neurol Neurosurg Psychiatry 2006;77:2833.

25 Price CC, Jefferson AL, Merino JG, Heliman KM, Libon DJ: Subcortical vascular dementia. Integrating neuropsychological and neuroradiologic data. Neurology 2005;65:376382.

26 Ylikoski R, Ylikoski A, Erkinjuntti T, et al: White matter changes in healthy elderly persons correlate with attention and speed of mental processing. Arch Neurol 1993;50: 818-824.

27 Ferris SH: Cognitive outcome measures. Alzheimer Dis Assoc Disord 1999;13:S140 S142.

28 Ferris SH: General measures of cognition. Int Psychogeriatr 2003;15:215-217.

29 Pantoni L, Basile AM, Pracucci G, Asplund K, Bogouslavsky J, Chabria H, Erkinjuntti T, Fazekas F, Ferro JM, Hennerici M, O’Brien J, Scheltens P, Visser MC, Wahlund L-O, Waldemar G, Wallin A, Inzitari D: Impact of age-related cerebral white matter changes on the transition to disability - the LADIS study: rationale, design and methodology. Neuroepidemiology 2005;24:51-62.

30 Lawton MP, Brody EM: Assessment of older people: self-maintaining and instrumental activities of daily living. Gerontologist 1969; 9:179-186.

31 Folstein MF, Folstein SE, McHugh PR: 'MiniMental State': a practical method for grading the cognitive state of patients for the clinician. J Psychiatr Res 1975;12:189-198.
32 Madureira S, Verdelho A, Ferro J, Basile AM, Chabriat H, Erkinjuntti T, Fazekas F, Hennerici M, O’Brien J, Pantoni L, Salvadori E, Scheltens P, Visser MC, Wahlund L-O, Waldemar G, Wallin A, Inzitari D; on behalf of the LADIS Study Group: Development of a neuropsychological battery for the Leukoaraiosis and Disability in the Elderly Study (LADIS): experience and baseline data. Neuroepidemiology 2006;27:101-116.

33 Cronbach LJ: Essentials of Psychological Testing, ed 4. New York, Harper \& Row Publishers, Inc, 1984

34 Fazekas F, Chawluk JB, Alavi A, Hurtig HI, Zimmerman RA: MR signal abnormalities at 1.5 T in Alzheimer's disease and normal aging. Am J Neuroradiol 1987;149:351-356.

35 Van Straaten ECW, Fazekas F, Rostrup E, Scheltens P, Schmidt R, Pantoni L, Inzitari D, Waldemar G, Erkinuntti T, Mäntylä R, Wahlund L-O, Barkhof F: Impact of white matter hyperintensities scoring method on correlations with clinical data. The LADIS Study. Stroke 2006;37:836-840.

36 Farlow MR, He Y, Tekin S, Xu J, Lane R, Charles HC: Impact of APOE in mild cognitive impairment. Neurology 2004;63:18981901.

37 Sahcdev PS, Brodaty H, Valenzuela MJ, Lorentz L, Looi JCL, Wen W, Zagami AS: The neuropsychological profile of vascular cognitive impairment in stroke and TIA patients. Neurology 2004;62:912-919.

38 Perret E: The left frontal lobe in man and the suppression of habitual responses in verbal categorical behavior. Neuropsychologia 1974; $12: 323-330$

-39 Fontaine A, Azouvi P, Remy P, Bussel B, Samson Y: Functional anatomy of neuropsychological deficits after severe traumatic brain injury. Neurology 1999;53:1963-1968.

40 Lezak MD: Neuropsychological Assessment. New York, Oxford University Press, 1995.

41 Burgess PW: Theory and methodology in executive function and research; in Rabbit $\mathrm{P}$ (ed): Methodology of Frontal and Executive Functions. East Sussex, Psychological Press, 1997, pp 81-116. 